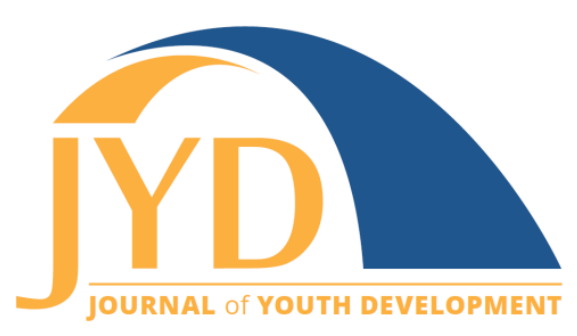

http://jyd.pitt.edu/ | Vol. 15 Issue 6 DOI 10.5195/jyd.2020.887 | ISSN 2325-4017 (online)

\title{
"Doing Our Part": What Motivates Black Family Engagement in an After-School Program
}

\author{
Amanda S. Case \\ Purdue University \\ amandacase@purdue.edu
}

\begin{abstract}
Researchers have demonstrated that Black caregivers (a) are more likely than caregivers of any other race to enroll their children in after-school programs, (b) face considerable challenges finding quality after-school programs, and (c) consider family engagement to be a hallmark of quality after-school programs. To date, however, researchers have largely ignored the voices of Black caregivers about what motivates and enables them to engage with their children's after-school programs. As a result, afterschool program staff report continued challenges effectively engaging Black families. The current case study aims to address this gap in the literature using evidence from participant observations, interviews with program staff, and focus groups with caregivers from the Downtown Boxing Gym, a communitybased after-school program in Detroit, Michigan that primarily serves Black youth. Results suggest caregivers were largely motivated to engage with the program because of the gains they observed in their children and themselves, causing them to feel thankful and sparking a desire to give back. Caregivers also named specific program practices that made it easier for them to participate, including explicit expectations and requests for family engagement and multiple ways for them to participate. Implications for increasing family engagement at other after-school programs are discussed.
\end{abstract}

Key words: after-school programs, family engagement, Black families, caregiver involvement

\section{Introduction}

Let's begin with a fact: The United States is not as safe for Black youth as it is for their nonBlack peers. The data confirms this. Black youth are 1.5 times more likely to die than White youth, 1.8 times more likely to die than Latinx youth, and nearly 3 times more likely to die than Asian youth (Kids Count, 2020). Unlike their non-Black peers, one of the leading causes of death for Black youth, and especially for Black boys, is homicide (Heron, 2019), often at the hands of police (Edwards et al., 2019). And while death is certainly the most severe threat Black

(cc) EY New articles in this journal are licensed under a Creative Commons Attribution 4.0 License. This journal is published by the University Library System, University of Pittsburgh and is cosponsored by the University of Pittsburgh Press. The Journal of Youth Development is the official peer-reviewed publication of the National Association of Extension 4-H Youth Development Professionals and the National AfterSchool Association. 


\section{Black Family Engagement in After-School Programs}

youth face, it is not the only threat; Black youth must negotiate innumerable risks created by systemic and systematic racism both inside and outside of school (Coates, 2015). For these reasons, and perhaps now more than ever, Black children and adolescents need safe and nurturing spaces to go after school.

For decades, the parents and caregivers of Black youth have enrolled their children in afterschool programs at rates that far exceed other parents (Hynes \& Sanders, 2011) not only so their children can be safe from a world that threatens their futures and lives, but also so their children have additional opportunities for growth and development (Hynes \& Doyle, 2009). However, Black caregivers have consistently reported difficulties finding accessible and affordable high-quality after-school programming (Afterschool Alliance, 2014). According to Robinson and Fenwick (2007), Black caregivers look for after-school programs with appropriately trained staff, activities that combine academics and fun, and of particular importance to this paper, programs that encourage family engagement.

To date, researchers have not explored what allows Black caregivers to be engaged in their children's after-school programs. As a result, even though the caregivers of Black youth are more likely to send their children to after-school programs, they are not being engaged to the extent that they could be. The purpose of this case study is to learn from Black caregivers about what motivates and enables them to be engaged in one community-based after-school program.

\section{Black Families and After-School Programming}

Black youth are more likely than their peers to be involved in after-school programming, participating at rates twice that of White and Latinx youth (Afterschool Alliance, 2014; Hynes \& Doyle, 2009). What is more, Black youth spend more time in after-school programming than their peers, with $23 \%$ of Black youth spending 5 or more hours each week in after-school programming in comparison to only $10 \%$ of White youth (Afterschool Alliance, 2014). Based on these numbers, researchers have concluded that "afterschool programs represent a major developmental context for significant portions of African American children, while White children have considerably less exposure to these environments" (Hynes \& Sanders, 2011, p. 470).

Research is inconclusive on why Black youth are more involved in after-school programming than their non-Black peers. However, researchers have suggested myriad factors play a role. For example, Hynes and Sanders (2011) investigated the relationship between after-school 


\section{Black Family Engagement in After-School Programs}

program usage in Black and White families and four factors, including availability of caregivers, financial resources, preferences for care settings, and availability of programs. Their results suggested only two of those factors likely explain the higher participation rates of Black youth in after-school programming: the fact that proportionally more Black families are headed by single working mothers, thereby increasing the need for after-school programming; and that Black youth are more likely than their White peers to live in economically under-resourced neighborhoods, which may both increase the prevalence of after-school programs in their neighborhoods and cause caregivers to have more concerns about neighborhood risks should youth be left unsupervised after school. Other authors (e.g., Eccles \& Gootman, 2002; Woodland, 2008) have also attributed the Black-White gap in after-school program usage to the systemic racism Black youth face in schools, which causes Black caregivers to be even more motivated to find culturally relevant and supportive after-school programming that can counteract the discriminatory treatment Black youth experience at school.

Although Black youth participate in after-school programming more than their peers, the need for after-school programming among Black families is still unmet. Recent estimates suggest approximately $60 \%$ of Black caregivers whose children are not in after-school programming (or approximately 4.5 million youth) would enroll their children in after-school programming if it were available. However, Black caregivers report significant barriers to accessing programming, including lack of safe transportation to and from after-school programs and limited availability of high quality after-school programs in their neighborhoods (Afterschool Alliance, 2014).

To date, researchers have conducted few studies about the qualities Black caregivers are looking for in after-school programs. The exception is a study conducted by Robinson and Fenwick (2007) that collected data from 407 Black caregivers whose children were involved in after-school programs in four cities (Detroit, Milwaukee, Philadelphia, and Washington, D.C.). Their findings suggest Black caregivers believe strong after-school programs share several characteristics, including proximity to home or school, well-trained staff, activities that balance academics and fun, and programming that keeps youth happy and engaged. In addition, Black caregivers also mentioned high-quality after-school programs effectively communicate with parents and encourage caregiver involvement. Researchers have consistently supported the importance of these latter qualities regarding family engagement in broader research on afterschool programming. 


\section{Family Engagement and After-School Programming}

Bouffard and colleagues (2011) describe family engagement as a collaborative process in which youth-serving organizations "are committed to reaching out to engage families in meaningful ways and in which families are committed to actively supporting their children's learning and development" (p. 4). Fundamental to this definition is the understanding that families play a crucial role in student success, a fact well supported by research (e.g., Fan \& Chen, 2001; Henderson \& Mapp, 2002; Nakagawa, 2000; Sanders, 2012).

Because of the essential function families serve in supporting student outcomes, researchers identify family engagement as a key component of quality after-school programs (Bodilly \& Beckett, 2005; Bouffard et al., 2011; Harvard Family Research Project, 2006; Little et al., 2008; Metz et al., 2008; Westmoreland \& Little, 2006). Paulta and colleagues (2016) named "strategies to engage families" as one of three core characteristics that increase the quality of after-school programming (p. 50). Similarly, Bodilly and Beckett (2005) included "integrated family and community partnerships" in their list of nine quality domains that likely contribute to effective after-school programming (p. 106). Findings such as these have led after-school researchers and practitioners to conclude that family engagement increases the effectiveness of after-school programming (Palmer et al., 2009).

Effectively engaging families in after-school programming is beneficial not only to the youth served by the program, but also to the youths' families and to the program itself (Bouffard et al., 2011). When families are engaged, youth are more likely to participate in after-school programs (Borden et al., 2005; Furstenberg et al., 1999; Russel et al., 2008) and persist in those programs for longer (Deschenes et al., 2010). What is more, family engagement in afterschool programming leads to better relationships between youth and program staff (Intercultural Center for Research in Education \& National Institute on Out-of-School Time [NIOST], 2006) and higher school attendance, involvement, and achievement (NIOST 2006; Weiss \& Brigham, 2003), especially for youth of color (Epstein, 2011; Olivos, 2007; Quezada, 2014).

But the benefits of family engagement are not exclusive to youth. Family engagement in afterschool programming is also beneficial to the whole family, resulting in more positive parentchild relationships at home (Grossman et al., 2002; Harris \& Wimer, 2004), increased caregiver involvement in and communication about schoolwork (Chaplin \& Capizzano, 2006; U.S. Department of Education, 2003), and greater family involvement at school (Riggs \& Medina, 


\section{Black Family Engagement in After-School Programs}

2005; Reisner et al., 2004). In addition, after-school programs also benefit from family engagement. By maintaining effective communication between families and the program and ensuring families are involved in the development of program policies, procedures, and activities, after-school programs can more effectively respond to student and family needs, thereby reducing dropout, and ultimately serving youth more effectively (BOSTnet, 2019; Bouffard et al., 2011). Programs that effectively engage families also receive more support from families and the broader community (Intercultural Center for Research in Education \& NIOST, 2005). Based on these findings, several researchers have concluded that after-school programs must prioritize family engagement (BOSTnet, 2019; Bouffard et al., 2011; NIOST 2006) if they are to effectively serve youth, especially youth in marginalized communities (Paulta et al., 2016).

Despite the known benefits of family engagement, after-school personnel routinely report challenges involving families (Bouffard et al., 2011). Some of these challenges result from the negative experiences families-and especially economically marginalized families and families of color-have had trying to be involved in their children's schools. Caregivers of racially and economically marginalized students are rarely considered collaborative partners in their children's success, viewed instead by school personnel as problems to be fixed (Olivos, 2007) or as bystanders with little interest in their children's educations (Crowson \& Boyd, 2001; Ishimaru, 2017). Because of systematic exclusion, few caregivers of color have opportunities to collaborate with educators, and when that collaboration happens, it is often negative (Auerbach, 2012; Ishimaru, 2017). In addition, a host of pragmatic challenges interrupt family engagement in after-school programming, including time and work constraints for both families and program personnel, difficulties securing transportation or childcare for family engagement events, cultural or language differences that cause program personnel to perceive communication to be more challenging, inadequate staff training on family engagement, and even the perception amongst program staff that families do not want to be involved (Bouffard et al., 2011; Deschenes et al., 2010; Weiss \& Brigham, 2003). Even with these challenges, many after-school program practitioners and researchers are committed to identifying mechanisms for effective family engagement based on the understanding that failing to do so compromises program effectiveness (NIOST, 2006).

To date, several studies and reports have outlined steps after-school programs can take to effectively engage families. Though the specific suggestions differ across publications, researchers (e.g., Bouffard et al., 2011; Kakli et al., 2006) have generally agreed on several 


\section{Black Family Engagement in After-School Programs}

core strategies to promote family engagement: supporting the basic needs of families so they can engage in after-school programs (e.g., providing transportation and childcare, offering engagement activities at convenient times, etc.; Burkhauser et al., 2008; Weiss \& Brigham, 2003); building respectful, trusting relationships with families (Caspe et al., 2019; Kakli et al., 2006; Lopez, 2017); hiring staff who are dedicated to or specifically responsible for family engagement activities (Bouffard et al., 2011; Kakli et al., 2006); offering a variety of ways that families can be engaged, including in program leadership, so they can select the engagement activities that feel most comfortable to them (Bouffard et. al, 2011; Caspe et al., 2019; Lopez, 2017); and including family engagement not only as a central mission of the program but also in program assessments (Caspe et al., 2019; Kakli et al., 2006).

Although the research noted above provides multiple suggestions about how after-school programs can effectively engage caregivers, gaps remain in our understanding of how families-and especially Black families-can effectively engage with their children's after-school programs. Some of these gaps are simply due to what is currently known; research on family engagement in after-school settings is relatively new (Weiss \& Brigham, 2003), commencing in the early 2000s only after the federal government started providing direct federal funding to after-school programs (Bartko, 2005). But other knowledge gaps are due to how research on family engagement in after-school settings is conducted. None of the references noted above about effective family engagement practices gathered data from caregivers. Instead, these studies relied on data collected from program personnel. As a result, caregiver perspectives have not been integrated into family engagement practices. The current study is an attempt to address that gap by learning from Black caregivers about what motivated and enabled them to be engaged in one community-based after-school program that primarily serves Black youth.

\section{Methods}

\section{Research Design}

To learn more about Black caregivers' experiences of and mechanisms for engaging with their children's after-school programs we conducted a descriptive case study (Yin, 2014) of the Downtown Boxing Gym (DBG). The DBG is a community-based after-school program with the broad mission of fostering the academic and socioemotional development, health and wellness, and college and career readiness of students ages 8 to 21 from Detroit, Michigan. To meet this mission, the gym provides year-round boxing instruction, mentoring, and tutoring 5 days a week after school at no charge. In addition, the gym provides supplemental weekend 


\section{Black Family Engagement in After-School Programs}

opportunities for STEM instruction, community service, and special outings, again at no cost to families. To ease the burden of transportation, the gym provides free transportation to and from all programming. DBG also provides students with healthy meals and snacks at all gym events. DBG can provide these comprehensive services at no cost to families through foundation grants and individual and corporate donations; the gym is also registered as a 501(c)(3).

Although the program is open to all students regardless of race or socioeconomic background, over $90 \%$ of DBG students identify as Black or African American and approximately $99 \%$ of them reside in economically marginalized households. For reference, approximately $80 \%$ of students in Detroit City School District are Black and 88\% qualify for free or reduced-price meals at school (Data Driven Detroit, 2017).

Since it opened in 2007, DBG has served over 550 youth, approximately $35 \%$ of whom are still enrolled in the program and approximately $60 \%$ whom have graduated from the program. Of those graduates, $100 \%$ have graduated from high school and $98 \%$ were accepted to and enrolled in a 2-year or 4-year college or university. In comparison, Detroit Public Schools, which DBG students primarily attend, have a high school graduation rate of approximately $77 \%$ and a college enrollment rate of less than 40\% (Data Driven Detroit, 2017; Tanner, 2017).

The author selected case study methodology because it enables the in-depth examination of a single, complex phenomenon using multiple sources of evidence (Yin, 2003). Unlike experimental or quasi-experimental methods, case studies are particularly suited to investigating "how" and "why" questions about an ongoing event, person, or program within its real-world context (Yin, 2014). The current case study utilized three sources of evidence: (a) participant observation by the author, (b) interviews with the executive director (ED) of the DBG, and (c) focus groups with caregivers whose children participated in DBG.

\section{Participant Observation}

Since 2013 the author has served as an external evaluator and consultant for DBG. In this role the author has spent considerable time in the gym collecting data, meeting with staff and students, and engaging in participant observation. As Jorgensen (2015) describes, participant observation is a qualitative methodology in which the researcher interacts with people in their natural environments, collecting information about phenomena that are typically unseen by outsiders. Because the studied phenomena are often inaccessible to outsiders, participant observation requires researchers to establish and maintain relationships with individuals in the 


\section{Black Family Engagement in After-School Programs}

context of interest. In doing so, participant observation enables researchers to gain access to the perspective of people who are "insiders or members of particular situations and settings" (Jorgensen, 1989, p. 13). For the sake of the current study, the author analyzed notes from approximately 10 hours of participant observations conducted on multiple days from 20152017. These participant observations were for relationship-building (i.e., becoming a recognizable face to students and staff at the gym) and research (i.e., learning the daily routines of the gym, observing interactions between students and staff) purposes.

\section{Interviews With the Executive Director}

The author conducted three informal interviews by phone with the ED of DBG regarding family engagement in the gym. One of those interviews was in preparation for the caregiver focus groups described below. The other interviews occurred in March 2019 and March 2020 as this manuscript was being written. Questions about family engagement were folded into broader conversations about the ongoing collaboration between the author and DBG. Interview topics particularly relevant to this study included the proportion of families who are engaged in the gym, the ways caregivers are typically engaged in the gym, and barriers the gym has faced in increasing family engagement. The author analyzed notes from each of those interviews for the current study.

\section{Focus Groups With Caregivers.}

The author and two undergraduate students conducted semi-structured focus groups in summer 2016. The focus groups were structured around four topics: how caregivers learned about the gym (e.g., "how did you first hear of the Downtown Boxing Gym?"), why they wanted their children to be involved in the gym (e.g., "How come you wanted your child to join?"), how their children and their families have been affected by gym involvement (e.g., "What impact has the gym had on your child?" "What impact has the gym had on your family?"), and what they see as the cause for the changes they have seen in their children and families (e.g., "What about the gym has caused the changes you've seen in your child and your family?"). In keeping with the format of semi-structured focus groups, follow-up questions were asked on these topics and participants were encouraged to bring up additional topics they felt were important to explain their experiences.

The ED of the gym invited all DBG caregivers to participate in one of two focus groups held on two consecutive days in summer 2016. The resulting focus groups, which were ultimately comprised based on caregiver interest and availability, ranged in size from 5 to 15 participants. 


\section{Black Family Engagement in After-School Programs}

A total of 20 caregivers participated in the focus groups, including 14 females and 6 males. Most of the participants self-identified as African American $(N=17)$, with the remaining three caregivers self-identifying as Latinx. Only data from the African American caregivers were included in this analysis.

All focus groups occurred at DBG, in a room where only research team members and participants were present. All focus groups were audio- and video-recorded. Before initiating the discussion, the researchers introduced themselves and reviewed the purpose of the focus group, which was described as "learning about your experience of having your child involved in the Downtown Boxing Gym." Participants were then informed of the "rules" of the focus group, including that "no topic is off limits," participants should feel free to jump in when they have something to share, and that responses would remain confidential. After this introduction, participants signed consent forms and were then asked to share their name, the name of their child/children who attend the gym, and how long they had been involved with the gym. Focus groups lasted for between 55 and 75 minutes, with the duration being determined by the participants.

\section{Data Analysis}

Undergraduate students in the author's research team transcribed the audio recordings of the focus groups verbatim. The author and two undergraduate students (who were not the same students that co-led the focus groups) analyzed the transcriptions; only the first author analyzed the participant observation and interview notes. All analysis was conducted using a thematic analysis approach.

Thematic analysis is a flexible approach that involves identifying common themes represented in a data set (Vaismoradi et al., 2013). Before commencing, thematic analysis requires researchers to make several decisions (Braun \& Clarke, 2006), including whether the research is inductive (i.e., data driven) or deductive (i.e., theory driven) and whether the entire data set will be analyzed or only portions relevant to a particular topic (Braun \& Clarke, 2006). The current study used an inductive approach because of the lack of existing research regarding why and how Black caregivers engage with their children's after-school programs. As such, codes and themes were derived directly from the data rather than drawn from a priori theories. In addition, because this paper focused on understanding what motivated and enabled caregivers to be engaged with the gym, only data relevant to those topics were analyzed. 


\section{Black Family Engagement in After-School Programs}

In keeping with the thematic analysis phases outlined by Braun and Clarke (2006), each of the three sources of data (participant observation, interviews, and focus groups) were analyzed in six steps. First, we familiarized ourselves with the data by reading and re-reading the text in its entirety. After we felt sufficiently comfortable with the data, we generated initial codes, focusing on identifying notable features of the entire data set. Third, we organized the codes into potential themes and pulled together exemplar data relevant to each theme. Once gathered, those themes and exemplars were compared to the entire data set to ensure they retained their original meaning. Fifth, we defined and named each of the themes and developed an overarching thematic structure that organized the analysis into themes and subthemes. Finally, we selected particularly vivid exemplars for each of the themes and subthemes.

\section{Results}

\section{How Are Families Engaged in the Gym?}

According to the ED of DBG, the gym has been "relatively successful" at fostering family engagement. In the interviews that were conducted in 2019 and 2020 the ED shared that approximately "five to 10 " caregivers (including parents, grandparents, and either blood- or non-blood-related uncles and aunts) can be found volunteering or working at the gym daily. Though some of these caregivers are "regulars," spending time at the gym several days a week, others are only present from time to time. These estimates were consistent with my own observations. Over the approximately 10 hours I spent conducting participant observations from 2015 to 2017, caregivers were always present and often differed from day to day. The ED also shared that at special events such as tournaments, benefits, family nights, and community service events, more than $50 \%$ of student caregivers are regularly present.

The ED attributed these high rates of family engagement to the multiple ways caregivers can engage with the gym. According to the ED, there are four primary ways caregivers are involved: as volunteers who tutor, chaperone trips, and coach students; as "Ambassadors" who spread the word about the gym and advocate on the gym's behalf; as members of the "Family Support System" who "step up to make sure other students are well taken care of;" and as employees who work as drivers, tutors, front desk staff, and kitchen staff. These categories of engagement also matched my own observations. Whereas I saw some caregivers participating in formal ways (e.g., working the front desk, preparing meals for students, serving as members of the coaching staff, etc.), others participated informally (i.e., playing chess with youth, helping with tutoring, assisting with maintenance, etc.). In addition, I also observed caregivers engaging 


\section{Black Family Engagement in After-School Programs}

during drop-off or pick-up times by talking with staff or other youth in the program or, on more than one occasion, taking a few moments to pick up garbage or rearrange chairs. As a participant observer I did not ask caregivers about their motivation for engaging in these formal and informal ways. However, in the focus groups caregivers spoke at length about how the gym has impacted both their children and themselves, which they then tied to their motivation for wanting to be involved.

\section{What Motivates Caregivers to Want to Be Engaged With the Gym?}

Most of the caregivers described wanting to be engaged with the gym because they appreciate what the gym does for their children. For example, one caregiver stated, "[Everyone at the gym] goes out of their way for these children. That's why I don't mind supporting them." Similarly, another caregiver remarked, "They provide so much for these kids so if they call, [caregivers] will all come when they need us."

When asked what aspects of the gym they were appreciative of, all the Black caregivers who participated in the focus groups first mentioned something about safety. One father mentioned, "I'm comfortable if [my son] is here because I know he's safe;" another mother stated, "[I] don't have to worry if [my son] is here-I know he'll be safe." Similarly, several caregivers described the gym as a "close-knit family" where "everyone looks out for each other." Because of these characteristics, many caregivers shared they felt "more comfortable" and "less worried" about their children during out-of-school time hours.

Beyond the safety provided by the gym, many of the caregivers reported the gym had a significant impact on their children's overarching sense of self. For example, virtually all the caregivers explicitly stated their children had become "more confident" since starting at the gym and many named specific ways they had seen this confidence manifest. One caregiver noted, for example, that her daughter "knows now that she can tell somebody, 'no, that's not how you're gonna talk to me and that's not how you're gonna treat me."'

Many caregivers also described increases in their children's emotional and behavioral "selfcontrol." For example, several caregivers shared their children stopped getting into fights at school after starting at the gym. Other caregivers stated that although they used to describe their children as "angry" before joining the gym, that descriptor no longer applied because their children were now able to "control" their feelings more effectively. 


\section{Black Family Engagement in After-School Programs}

Perhaps because of students' increased confidence and self-control, all the caregivers remarked on the behavioral changes they noticed since their children joined the gym. Some of these changes were evident at home. For example, multiple caregivers stated their children had become more respectful and mature, as evidenced by their children "listening to me more" and having more "willingness to do what [they're] supposed to do." Other behavioral changes were especially evident at school. Almost all caregivers specifically cited improvements in their children's grades and two caregivers also mentioned their children had made the honor roll. Several caregivers also spoke about positive changes in their children's "attitude about school" overall.

Unanimously, caregivers expressed considerable gratitude for the changes the gym fostered in their children. In addition, many caregivers expressed appreciation for the ways the gym had also benefitted them. For example, one mother shared, "the gym has had an impact that is not only on [my daughter's] life, but it has made me a better mom as well, and a proud mom." Several caregivers echoed this sentiment, sharing that being involved in the gym had made them "better parents."

Some caregivers attributed their improvement as parents to the "[parenting] tools" they learned at the gym. For example, several caregivers mentioned that the founder of the gym often provides caregivers with "guidance" and "resources" about how to handle parenting dilemmas. Because of this guidance, other caregivers mentioned they have become better at keeping "on track" of their children's schoolwork and "understand[ing] the ways [their children] feel." Caregivers also mentioned the gym has brought their family "closer together" because "[the gym] makes us spend time together as a family." Finally, several caregivers mentioned they felt more prepared to care for their children because the gym gave them renewed hope overall: "It's not just the kids who [the gym] gives hope for. It gives me hope . . . too."

For many of the caregivers, being thankful motivated them to engage with the gym and give back in any way they could. For example, as one father shared, "I'm so grateful to the gym, so whatever small amount that I can help with, I do." Similarly, another caregiver said, "The gym plays a significant part not just in the kids' lives, but in the parents' lives as well, so ... we have to get involved." 


\section{What Enables Caregivers to Be Engaged the Gym?}

In addition to describing what motivated them to engage with the gym, most of the caregivers also talked about what enabled them to be involved. Overall, these narratives seemed to center around three main themes: the shared expectation at the gym for caregiver involvement, the gym's open communication with caregivers marked by explicit requests for involvement, and the multiple ways caregivers can be involved at the gym.

As one grandfather described, "At a lot of places, it's like a drop and roll. You drop them off and you just keep on rolling, ... [at DBG], they want you to stay." This statement captured what many of the caregivers described as the "expectation" at the gym that "parents should help out." When most of the caregivers described this expectation, they seemed to attribute it to the overarching culture of the gym. For example, as one mother said, "it's like we all do what we can for each other [because] we are a team here." Similarly, another mother proclaimed, "You come in here, you have to help, and that's what we tell new parents, too." Based on these statements, it seems the expectation for caregiver engagement is held not only by gym staff but also by caregivers themselves.

Many of the caregivers described their involvement at the gym starting because they were asked to help, or in some cases, told they needed to be involved. Some of these requests came directly from other caregivers. As one father stated, "I will say this, if you're not helping out I'm gonna ask you to help out because you have to get involved." Other requests came from staff. For example, one father shared his story of how he started helping out at the gym:

I used to just drop [my son] off and leave. [The founder of the gym] said, "Nah, man, you know about boxing, why don't you just be still for a minute-help out around the gym." That was 7 years ago, and I been here every day since.

Several other caregivers endorsed similar experiences in which the founder or other staff members "called [them] out" to get more involved at the gym.

Several caregivers noted they accepted the requests for their involvement because DBG staff members were open and welcoming to caregivers: "Everyone here is approachable. You can walk up and talk to them and they take the time to listen." As a result, many caregivers also felt the staff understood how they could or could not give back to the gym. The notion that staff members were "approachable" was reinforced by data collected during participant observations. At least once during each observation session a staff member greeted by name a caregiver who walked into the gym. The interactions that followed appeared relaxed and comfortable, 


\section{Black Family Engagement in After-School Programs}

oftentimes punctuated with laughter and smiles from both the caregivers and the staff members.

When discussing how families can engage with the gym, caregivers named a variety of activities such as volunteering at the gym, "driving kids to out of town [tournaments]," and even buying necessary equipment: "I came in here one day and I was like 'Oh my god, it's so hot!' So, I just went to [the store] and bought fans." In these examples, the caregivers described the range of ways they could engage with the gym.

For many of these caregivers, the fact that there were multiple ways they could engage with the gym was precisely what enabled them to contribute. For example, one mother stated, "Money is pretty tight for us, so I can't be the one to go out and buy stuff or get things for the kids. But I can give my time, so I'm wrapping hands and I'm helping in the kitchen. That's my way of giving back." Another father reinforced this idea, naming the variety of ways that caregivers participate: "At the old gym parents used to come in and fix the plumbing or clean the floors. Now [in the new gym] you got parents helping with homework or playing chess or helping with snack or stepping in to coach." Particularly noteworthy in these statements was the idea that caregivers believed these various forms of involvement were all viewed as equally valuable by program staff and other caregivers. As one mother said, "Everybody does their part."

\section{Discussion}

Researchers have identified family engagement as an important contributor to quality afterschool programs, especially for students of color (e.g., Epstein, 2011; Olivos, 2007; Quezada, 2014), and have provided specific suggestions for how after-school programs can engage families (e.g., Kakli et al., 2006). However, program staff continue to report difficulties getting families engaged (e.g., Bouffard et al., 2011; Deschenes et al., 2010). Some of these difficulties may be because there is still a lot that is unknown about how to effectively engage families in out-of-school time programming. As Weiss and Brigham (2003) explained, research on family engagement in after-school programs is still in its infancy. What is more, most of what we currently know about effective family engagement in after-school settings is based on data collected from program staff rather than from caregivers. The current study aimed to address some of these gaps by drawing on multiple sources of data to understand what motivates and enables Black caregivers to be engaged in one community-based after-school program. 
Results of the case study suggest that DGB has, indeed, been successful in engaging Black families. Based on participant observation, interview, and focus group data, Black caregivers are regularly involved in the daily functioning of the gym, with at least a handful of caregivers (and oftentimes different caregivers) present at the gym each day. These caregivers are engaged in a variety of formal and informal ways, oftentimes based on their interests, expertise, and resources.

Further, caregivers shared there are both specific reasons why they wanted to be involved in the gym and practices of the gym that enabled them to be involved. Particularly motivating for caregiver participation was the positive impact the gym had on their children and their family, which generated feelings of thankfulness and gratitude. For the caregivers that cited such feelings, this gratitude caused them to want to give back to the gym precisely because they could so clearly see how their families were benefitting from the atmosphere of and programming provided by the gym. But that motivation was not the only reason why caregivers said they were able to be involved. Caregivers also cited specific mechanisms in place at the gym that made it easier, and therefore more likely, for them to be engaged, including shared expectations amongst gym staff and other caregivers that they would be involved, the gym's open communication with caregivers, and the multiple roles caregivers could play at the gym.

Some of the study findings echo previous research about how to foster family engagement in after-school programs. For example, in line with Bouffard and colleagues' (2011) recommendation that programs should build trusting relationships with families, the caregivers described feeling more drawn to family engagement opportunities because the staff members knew them well enough to understand how they could best be involved in the gym. In addition, similar to existing suggestions that programs should use a variety of family engagement practices (Kakli et al., 2006), caregivers also described feeling able to be engaged in the gym because there were a variety of ways to do so.

Other findings from the current study extend previous research about effective family engagement practices. Some of these extensions clarify and build upon existing recommendations. Though study findings indeed support researchers' assertions that effective communication and trusting relationships are important in fostering family engagement, the caregivers in the current study added specificity to that recommendation, describing that they felt especially motivated and able to engage with the gym because program staff and other 


\section{Black Family Engagement in After-School Programs}

caregivers explicitly asked them to be involved. Furthermore, in addition to confirming previous research about the importance providing different ways for families to be engaged, DBG caregivers also shared that it was helpful to their engagement that gym staff and other caregivers gave equal value to those different ways to engage. As a result, caregivers who differed in terms of expertise and resources could find ways to engage that felt meaningful to themselves and the program.

Finally, some of the findings from the current study identify factors that previous research has not recognized as important for family engagement. Most notably, caregivers tied their desire to be engaged with the gym to their awareness of and thankfulness for how the gym has benefitted their families. To date, this idea of what motivates families to be engaged in afterschool programs has not received much attention in the research literature but could be useful in considering how programs like DBG can foster engagement from Black caregivers.

\section{Implications for Youth Development Programs}

DBG is a unique program with a specific culture that exists in a particular context serving a distinct population. Because of this, what enables DBG to engage families effectively will not work for all after-school programs. However, by directly capturing what motivates and enables Black caregivers to be engaged in DBG, findings from the current study may hold implications for how other after-school programs foster family engagement from the Black families they serve. Findings suggest three practices may be especially useful for fostering family engagement amongst Black caregivers: ensuring caregivers are aware of program impacts, devising a range of valued ways for caregivers to be involved, and asking explicitly for caregiver involvement (see Table 1). 
Table 1. Strategies After-School Programs Can Use to Engage Black Families

\begin{tabular}{|c|c|}
\hline Strategy & Suggested steps \\
\hline $\begin{array}{l}\text { 1. Inform caregivers of } \\
\text { program impacts. }\end{array}$ & $\begin{array}{l}\text { - Provide caregivers with newsletters, reports, or websites that } \\
\text { convey program impacts. } \\
\text { - Visually convey program achievements through banners, murals, or } \\
\text { swag. } \\
\text { - Have informal conversations with caregivers at drop-off, pick-up, or } \\
\text { other convenient times about student gains. }\end{array}$ \\
\hline $\begin{array}{l}\text { 2. Devise multiple ways for } \\
\text { caregivers to engage with } \\
\text { programs. }\end{array}$ & $\begin{array}{l}\text { - Survey caregivers about their interests, skills, or experiences they } \\
\text { would like to share with students. } \\
\text { - Create a "wish list" of family engagement activities that is sensitive } \\
\text { to caregiver resources. } \\
\text { - Devise ways for families to be engaged outside of program hours. }\end{array}$ \\
\hline $\begin{array}{l}\text { 3. Directly ask caregivers to be } \\
\text { engaged. }\end{array}$ & $\begin{array}{l}\text { - Create program materials that ask caregivers to be engaged and } \\
\text { list family engagement opportunities. } \\
\text { - Train staff to ask for and encourage family engagement. } \\
\text { - Create a program culture in which caregivers can encourage other } \\
\text { caregivers to be engaged. }\end{array}$ \\
\hline
\end{tabular}

\section{Ensuring Caregivers Are Aware of Program Impacts.}

DBG caregivers engaged with the gym because they knew their children were safe in and benefitting from the program. For Black caregivers in particular, keeping their children safe from discrimination and other threats is a key concern (Hynes \& Sanders, 2011). Therefore, caregivers at the gym felt grateful because the gym not only assuaged their concerns about their children's safety (Afterschool Alliance, 2014) but also supported their children's growth and development, which incited their desire to give back to the gym. These findings suggest afterschool programs might motivate caregiver involvement by making caregivers aware of program impacts.

Ideally, program impacts would be evident to caregivers. For example, given that most afterschool programs aim to increase positive competencies (e.g., coping skills, self-efficacy, academic achievement, etc.) and decrease problem behaviors (e.g., school misbehavior, substance use, aggression, etc.; Durlak et al., 2010; Roth \& Brooks-Gunn, 2016;), one would 


\section{Black Family Engagement in After-School Programs}

hope caregivers could see such changes in their children on their own. However, that may not always be the case. Therefore, programs may want to be strategic in how they communicate with caregivers both about overall program benefits and about child-specific gains.

To communicate with caregivers about the benefits of the program overall, after-school programs can adopt some of the one-way communication strategies often used by teachers and schools (Graham-Clay, 2005). These strategies, which commonly take the form of newsletters, reports, or websites, could reinforce the program's mission while also conveying general program impacts related to that mission. For example, one of the main objectives of the gym is to increase academic engagement and success. Therefore, in their communications with caregivers, gym staff highlight relevant program impacts such as that $100 \%$ of their students score above national averages in learning interest, critical thinking, and academic motivation, and that their students have achieved a 30\% increase in school attendance (DBG, 2018). In conveying program-wide impacts such as these, after-school programs can direct caregivers' attention to similar accomplishments in their own children.

In addition to these written, one-way communication strategies, after-school programs may also want to convey program impacts to caregivers visually. Programs could hang up signs or banners that publicize their program achievements or create murals or other larger visual displays of their accomplishments if their space allows. In addition, if programs provide t-shirts, bags, or other "swag" to students that caregivers are likely to see, programs could also use these materials to convey program impacts.

Caregivers in the study were particularly motivated to engage with the gym because of their children's individualized growth and development. To ensure caregivers recognize these personalized gains, after-school programs can, again, look to schools for ideas. The most common ways teachers have historically communicated with caregivers about student progress is through reports and conferences (Williams \& Cartledge, 1997); after-school programs could adopt these strategies to share student improvements. However, these methods require considerable time and resources that after-school programs may not have. Therefore, program personnel could also use informal communication methods to convey student gains. For example, although drop-off and pick-up times are busy at DBG, caregivers routinely chat with DBG staff about their children at these times. Staff at other after-school programs could take advantage of these brief interactions with caregivers to share their observations about student growth. Program staff could also use phone calls, texts, and emails to alert caregivers to 


\section{Black Family Engagement in After-School Programs}

student improvements, especially if these improvements have not yet generalized to other settings where parents may have observed them first-hand.

\section{Devising Multiple Ways for Caregivers to Be Involved}

According to the caregivers in the current study, they could be involved in the gym because there were multiple ways for them to participate. These findings make sense; just as students who participate in after-school programs have different strengths and resources, so too do their caregivers. Therefore, if after-school programs want caregivers to be involved, they should identify a range of ways for caregivers to participate.

One way programs could begin to identify various forms of family engagement would be to ask caregivers directly about their interests, expertise, and resources. For example, program personnel could survey caregivers, asking them to list topics they are passionate about, experiences they have had, or skills they hold that they could share with the students. Such topics, experiences, and skills need not be directly related to the mission or structure of the program. For instance, one of the caregivers at the gym is a professional barber who gives back to students and families at the gym by providing free haircuts. Providing free haircuts is not the mission of the gym, but it enables this caregiver to use his expertise to engage with the gym while also supporting student self-confidence.

Beyond gathering information to identify ways caregivers might be involved, programs could also develop a "wish list" that is sensitive to the varying resources caregivers have at their disposal. For example, whereas some caregivers may feel comfortable volunteering to tutor students, others many not feel they have the knowledge to help with academics. However, if a range of volunteer options (e.g., checking students in, distributing snacks, organizing materials, serving on the parent advisory board, giving financially, etc.) are on the wish list, caregivers with varying strengths, time, and resources could meaningfully contribute.

Furthermore, because not all caregivers have the flexibility to be present during program hours, programs should also identify ways for caregivers to be involved outside of program hours. At the gym, for instance, many of the caregivers have second-shift jobs that require them to work during after-school hours. To ensure these caregivers can still participate and support the gym's mission, caregivers can also sign up to provide "family support." In this role, caregivers carpool students to school in the morning or cook meals for families in times of need. 


\section{Black Family Engagement in After-School Programs}

\section{Explicitly Asking Caregivers to Be Involved}

One of the biggest barriers to caregiver involvement in schools is that they often do not feel welcome (Center for Comprehensive School Reform and Improvement, 2019). Based on what one DBG caregivers shared about other after-school programs, the same may be true of out-ofschool time activities, which "push [parents] out the door." Given this, if after-school programs want caregivers to be engaged, they should explicitly ask for their involvement.

Requests for family engagement can come in written or verbal form from program staff. Program materials distributed to caregivers could state that the program wants families to be involved and list the ways that families can be engaged. If the program requires students to sign contracts, program staff may also consider asking caregivers to sign contracts that signal their commitment to be involved in some way (Smith et al., 2011). So as not to prioritize certain types of involvement over others, however, such contracts should reflect the multiple ways caregivers can participate (Becker et al., 1997). Program administrators could also look first to caregivers for help and ensure staff members are trained to ask for and encourage caregiver participation.

In addition, caregivers may be more likely to participate if another caregiver asks them to. As caregivers in the current study described, they often take it upon themselves to tell other caregivers to help out and respond favorably to other caregivers' requests for involvement. Therefore, program personnel could prioritize building a program culture in which caregivers feel empowered to ask one another to participate. Some caregivers could also be asked to serve as family engagement liaisons (Howland et al., 2006), whose responsibility it would be to encourage and coordinate caregiver participation.

\section{Limitations}

Results of the current study should be considered with certain limitations in mind. First, the author has a longstanding relationship with the gym. At the time of data collection, the author had been involved with the gym for several years, had spent considerable time with program staff and students, and generally felt favorably towards the gym overall. Therefore, it is possible the author was primed to see positive family engagement practices in the data. To address this limitation, the team responsible for analyzing the focus group data included undergraduate students who had not spent time at the gym. However, a halo effect could have affected analyses and conclusions. 


\section{Black Family Engagement in After-School Programs}

Second, although all DBG caregivers were invited to attend the focus groups, participation was purely voluntary. As such, the experiences of only a small portion of the total caregiver population are represented in the data. The experiences of these caregivers may not be representative of all caregivers. It is possible, for example, that the caregivers who participated in the focus groups were more involved in the gym overall. If this were the case, their narratives may not reflect the experiences of less-involved caregivers.

Finally, findings from case studies are limited in their generalizability because the data they produce is context-dependent. For this reason, it is impossible to say whether the family engagement experiences of DBG caregivers are the same as caregivers involved in other afterschool programs. This is especially true in this case study, as DBG was founded by a Black man, is largely staffed by Black men and women, and predominantly serves Black families in a majority Black neighborhood using values and practices that were specifically designed to be culturally relevant for Black families. For this reason, the family engagement experiences of the Black caregivers at the DBG may differ from the experiences of Black caregivers in other organizations, especially if those organizations were not designed with Black families in mind.

\section{Conclusion}

Despite these limitations, the current study holds important implications for after-school programs across the country, especially those that serve Black families. Although Black caregivers are more likely to enroll their children in after-school programs than caregivers of all other races, up to this point their voices have not been represented in the literature about family engagement in after-school programs. As a result, after-school program personnel are in the precarious position of knowing family engagement is important in combating systemic inequalities but having limited guidance about how to encourage and support such involvement. By exploring the experiences of some Black caregivers from one after-school program, findings from the current study begin filling that gap by pointing to practices after-school programs could use to encourage family engagement.

\section{References}

Afterschool Alliance. (2014). America after 3PM: Afterschool programs in demand. Author. http://afterschoolalliance.org/documents/AA3PM-2014/AA3PM National Report.pdf 
Auerbach, S. (2012). School leadership for authentic family and community partnerships: Research perspectives for transforming practice. Routledge.

Bartko, W. T. (2005). The ABCs of engagement in out-of-school-time programs. New Directions for Student Leaderships, 2005(105), 109-120. https://doi.org/10.1002/yd.110

Becker, H. J., Nakagawa, K., \& Corwin, R. G. (1997). Parent involvement contracts in California's charter schools: Strategy for educational improvement or method of exclusion? Teachers College Record, 98(3), 11-36.

Bodilly, S., \& Beckett, M. K. (2005). Making out-of-school time matter: Evidence for an action agenda. RAND Corporation. https://www.rand.org/dam/rand/pubs/monographs/2005/RAND MG242.pdf

Bouffard, S. M., Westmoreland, H., O'Carroll, K., \& Little, P. M. (2011). Engaging families in out-of-school time programs. In H. Krieder \& H. Westmoreland (Eds.), Promising practices for family engagement in out-of-school time (pp. 3-20). Information Age.

BOSTnet (2019). Engaging families in out-of-school time programs toolkit: Tools to strengthen after school and youth program by increasing family involvement. Build the Out-of-School-Time Network.

https://cdn.ymaws.com/nafsce.org/resource/resmgr/Toolkits/Boston Engaging Families Out.pdf

Braun, V., \& Clarke, V. (2006). Using thematic analysis in psychology. Qualitative Research in Psychology, 3, 77-101.

Borden, L. M., Perkins, D. F., Villarruel, F. A., \& Stone, M. R. (2005).. New Directions for Youth Development, 105, 33- 49.

Burkhauser, M., Bronte-Tinkew, J., \& Kennedy, E. (2008). Building community partnerships: Tips for outof-school time programs. Practitioner Insights: Research-to-Results. Child Trends.

Caspe, M., Lopez, M. E., \& Hanebutt, R. (2019). The family engagement playbook. https://medium.com/familyengagementplaybook

Center for Comprehensive School Reform and Improvement. (2019). Getting parents involved in schools. http://www.readingrockets.org/article/getting-parents-involved-schools

Chaplin, D., \& Capizzano, J. (2006). Impacts of a summer learning program: A random assignment study of building educated leaders for life (BELL). Report prepared with support from the Smith Richardson Foundation and the William T. Grant Foundation as part of an evaluation study of the BELL summer learning program. The Urban Institute.

Coates, T. (2015). Between the world and me. Spiegel \& Grau.

Crowson, R., Boyd, W. (2001). The new role of community development in educational reform. Peabody Journal of Education, 76(2), 9-29.

Data Driven Detroit. (2017). Detroit City School District youth and family demographics. https://sdc.datadrivendetroit.org/profiles/97000US2612000-detroit-city-school-district-mi/ 
Journal of Youth Development | http://jyd.pitt.edu/ | Vol. 15 Issue 6 DOI 10.5195/jyd.2020.887 Black Family Engagement in After-School Programs

Downtown Boxing Gym. (2018). How we serve. Author. https://dbgdetroit.org/about-us\#mission

Deschenes, S. N., Arbreton, A., Little, P. L., Herrera, C., Grossman, J. B., Weiss, H. B., \& Lee, D. (2010). Engaging older youth: program and city-level strategies to support sustained participation in outof-school time. Harvard Family Research Project. https://www.wallacefoundation.org/knowledgecenter/Documents/Engaging-Older-Youth-City-Level-Strategies-Support-Sustained-ParticipationOut-of-School-Time.pdf

Durlak, J. A., Weissberg, R. P., \& Pachan, M. (2010). A meta-analysis of after-school programs that seek to promote personal and social skills in children and adolescents. American Journal of Community Psychology, 45(3-4), 294-309. https://doi.org/10.1007/s10464-010-9300-6

Eccles, J. S., \& Gootman, J. A. (Eds.). (2002). Community programs to promote youth development. National Academies Press.

Edwards, F. R., Lee, H., \& Esposito, M. (2019). Risk of being killed by police use of force in the United States by age, race-ethnicity, and sex. Proceedings of the National Academy of Sciences 116(34), 16793-16798.

Epstein, J. L. (2011). School, family, and community partnerships: Preparing educators and improving schools ( $2^{\text {nd }}$ ed). Westview

Fan, X., \& Chen, M. (2001). Parental involvement and students' academic achievement: A meta-analysis. Educational Psychology Review, 13, 1- 22.

Furstenberg, F. F., Cook, T. D., Eccles, J., Elder, G. H., Jr., \& Sameroff, A. (1999). Managing to make it: Urban families and adolescent success. University of Chicago Press.

Graham-Clay, S. (2005). Communicating with parents: Strategies for teachers. The School Community Journal, 15(1), 117-129.

Grossman, J. B., Price, M. L., Fellerath, V., Jucovy, L. Z., Kotloff, L. J., Raley, R., \& Walker, K. E. (2002) Multiple choices after school: Findings from the Extended-Service Schools Initiative. MDRC.

Harris, E., \& Wimer, C. (2004). Engaging with families in out-of-school time learning. Out-of-School Time Evaluation Snapshot No.4. Harvard Family Research Project.

Harvard Family Research Project. (2006). After school program quality assessment: Categories of standards. Author. https://archive.globalfrp.org/var/hfrp/storage/fckeditor/File/summit-2005standards.pdf

Henderson, A. T., \& Mapp, K. L. (2002). A New Wave of Evidence: The impact of school, family, and community connections on student achievement. Southwest Educational Development Laboratory.

Heron, M. (2019, June). Deaths: Leading causes from 2017. National Vital Statistics Reports, 68(6). https://www.cdc.gov/nchs/data/nvsr/nvsr68/nvsr68 06-508.pdf 
Journal of Youth Development | http://jyd.pitt.edu/ | Vol. 15 Issue 6 DOI 10.5195/jyd.2020.887

Black Family Engagement in After-School Programs

Howland, A., Anderson, J. A., Smiley, D., \& Abbott, D. J. (2006). School liaisons: Bridging the gap between home and school. The School Community Journal, 16(2), 47-68.

Hynes, K., \& Doyle, E. (2009). Changes in after-school program use: 1995-2005. Population Research Institute Working Paper \#0901. Pennsylvania State University.

Hynes, K., \& Sanders, F. (2011). Diverging experiences during out-of-school time: The race gap in exposure to after-school programs. The Journal of Negro Education, 80(4), 464-476. https://www.jstor.org/stable/41341153

Intercultural Center for Research in Education \& National Institute on Out-of-School Time. (2005). Pathways to success for youth: What counts in after-school. United Way of Massachusetts Bay.

Ishimaru, A. M. (2017). From family engagement to equitable collaboration. Educational Policy, 33(2), 350-385.

Jorgensen, D. L. (1989). Participant observation: A methodology for human studies. Sage. https://doi.org/10.4135/9781412985376

Jorgensen, D. L. (2015). Participant Observation. Emerging trends in the social and behavioral sciences: an interdisciplinary, searchable, and linkable resource. https://doi.org/10.1002/9781118900772.etrds0247

Kakli, Z., Kreider, H., Little, P., Buck, T., \& Coffrey, M. (2006). Focus on families! How to build and support family-centered practices in after school. Harvard Family Research Project and Build the Out-of-School Time Network.

Kids Count. (2020). Teen deaths from all causes by race in the United States. The Annie E. Casey Foundation Kids Count Data Center. https://datacenter.kidscount.org/data/tables/26-teendeaths-from-all-causes-byrace?loc $=1 \&$ loct $=1 \#$ detailed $/ 1 /$ any/false $/ 37,871,870,573,869,36,868,867,133,38 / 10,11,9,12,1,13$ 2295,294

Little, P. M. D., Wimer, C., \& Weiss, H. B. (2008). After school programs in the $21^{\text {st }}$ century: Their potential and what it takes to achieve it. Issues and Opportunities in Out-of-School Time Evaluation, 10, 1-12. https://archive.globalfrp.org/evaluation/publications-resources/after-schoolprograms-in-the-21st-century-their-potential-and-what-it-takes-to-achieve-it

Lopez, M. E., Caspe, M., \& Simpson, C. (2017). Engaging families in public libraries. Public Library Quarterly, 36(4), 318-333. https://doi.org/10.1080/01616846.2017.1354364

Metz, R. A., Goldsmith, J., \& Arbreton, A. J. A. (2008). Putting it all together: Guiding principles for quality after-school programs serving preteens. Public/Private Ventures. http://www.ppv.org/ppv/publications/assets/234 publication.pdf

Nakagawa, K. (2000). Unthreading the ties that bind: Questioning the discourse of parent involvement. Educational Policy, 14, 443-472. 
National Institute for Out-of-School Time (NIOST), (2006). Making the case: $A$ fact sheet on children and youth in out-of-school time. Wellesley Centers.

Olivos, M. E. (2007). The power of parents: A critical perspective of bicultural parent involvement. Peter Lang.

Palmer, K. L., Anderson, S. A., \& Sabatelli, R. M. (2009). How is the afterschool field defining program quality?: A review of effective program practices and definitions of program quality. Afterschool Matters, n9, 1-12.

Paulta, L. M., Lower, L., Anderson-Butcher, D., Gibson, A., \& Iachini, A. L. (2016). Examining the quality of $21^{\text {st }}$ century community learning center after-school programs: Current practices and their relationship to outcomes. Children \& Schools, 38(1), 49-56.

Quezada, R. L. (2014). Family-school, \& community engagement and partnerships: Working with culturally diverse families. Multicultural Education, 21(3/4), 2-4.

Reisner, E. R., White, R. N., Russell, C. A., \& Birmingham, J. (2004). building quality, scale, and effectiveness in after-school programs: Summary report of the tasc evaluation. Policy Studies Associates.

Riggs, N. R., \& Medina, C. (2005). The Generacion Diez after-school program and Latino parent involvement with schools. Journal of Primary Prevention, 26(6), 471- 484.

Robinson, G., \& Fenwick, L. (2007). More than homework, a snack, and basketball: Afterschool programs as an oasis of hope for black parents in four cities. Black Alliance for Educational Options.

Roth, J. L., \& Brooks-Gunn, J. (2016). Evaluating youth development programs: Progress and promise. Applied Developmental Science, 20(3), 188-202.

Russell, C. A., Mielke, M. B., \& Reisner, E. R. (2008). Evaluation of the New York City Department of Youth and Community Development out-of-school time programs for youth initiative: Results of efforts to increase program quality and scale in year 2. Policy Studies Associates.

Sanders, M. G. (2012). Sustaining programs of school, family, and community partnerships: A qualitative longitudinal study of two districts. Educational Policy, 26, 845-869.

Smith, J., Wohlstetter, P., Kuzin, C. A., \& De Pedro, K. (2011). Parent involvement in urban charter schools: New strategies for increasing participation. The School Community Journal, 21(1), 7194.

U.S. Department of Education. (2003). When schools stay open late: The national evaluation of the $21^{\text {st }}$ Century Learning Centers Program, first year findings. Author.

Vaismoradi, M., Turunen, H., \& Bondas, T. (2013). Content analysis and thematic analysis: Implications for conducting a qualitative descriptive study. Nursing and Health Sciences, 15, 398-405.

Weiss, A. R., \& Brigham, R. A. (2003). The family participation in after-school study. Institute for Responsive Education. 
Journal of Youth Development | http://jyd.pitt.edu/ | Vol. 15 Issue 6 DOI 10.5195/jyd.2020.887 Black Family Engagement in After-School Programs

Westmoreland, H., \& Little, P. M. D. (2006). Exploring quality standards for middle school after school programs: What we know and what we need to know. Harvard Family Research Project. http://www.hfrp.org/var/hfrp/storage/fckeditor/File/ summit-2005-summary.pdf

Williams, V. I., \& Cartledge, G. (1997). Passing notes to parents. Teaching Exceptional Children, 30-34. https://journals.sagepub.com/doi/pdf/10.1177/004005999703000106

Woodland, M. H. (2008). Whatcha doin' after school?: A review of the literature on the influence of afterschool programs on young black males. Urban Education, 43(5), 537-560. https://doi.org/10.1177/0042085907311808

Yin, R. K. (2003). Case study research: Design and methods ( $3^{\text {rd }}$ ed.). Sage.

Yin, R. K. (2014). Case study research: Design and methods (5 $5^{\text {th }}$ ed.). Sage. 